\title{
Identification of Specific Protein \\ Carbonylation Sites in Model Oxidations of Human Serum Albumin
}

\author{
Ani Temple, Ten-Yang Yen, and Scott Gronert \\ Department of Chemistry and Biochemistry, San Francisco State University, San Francisco, California, USA
}

\begin{abstract}
Human serum albumin (HSA) was subjected to oxidative stress and the locations of the resulting protein carbonyls were determined using mass spectrometry in conjunction with a hydrazide labeling scheme. To model oxidative stress, HSA samples were subjected to metal-catalyzed oxidation (MCO) conditions or treated with hypochlorous acid $(\mathrm{HOCl})$. Oxidation led to the conversion of lysine residues to 2-aminoadipic semi-aldehyde residues, which were subsequently labeled with biotin hydrazide. Analysis of the tryptic peptides from the samples indicates that the oxidations are highly selective. Under MCO conditions, only two of the 59 lysine residues appeared to be modified (Lys-97 and Lys-186). With $\mathrm{HOCl}$, five different lysine modification sites were identified (Lys-130, Lys-257, Lys-438, Lys-499, and Lys-598). These results strongly suggest that the preferred site of modification is dependent on the nature of the oxidant and that the process relies on specific structural motifs in the protein to direct the oxidation. The high selectivity seen here provides insights into the factors that in vivo drive the selective carbonylation of specific proteins in systems under oxidative stress. (J Am Soc Mass Spectrom 2006, 17, 1172-1180) (c) 2006 American Society for Mass Spectrometry
\end{abstract}

I $\mathrm{t}$ is well established that oxidative stress leads to a variety of protein modifications including carbonylation [1-4]. In particular, protein carbonyls have been identified as key biomarkers for disease [5-7] and aging [8-11]. Oxidation of the side-chain functional groups of lysine (Scheme 1), arginine, and proline to aldehyde groups (as well as threonine to a ketone) are common means of generating protein carbonyls [12, 13]. Studies by a number of workers, including Sohal [1417], have shown that protein carbonylation is selective and that only a subset of proteins is modified in systems under oxidative stress [18-26]. The underlying reasons behind this selectivity are not well understood. Although protein carbonylation has been characterized in numerous systems under a variety of conditions [2729], these studies only have targeted total carbonyl levels and the distribution between bound and free carbonyl species [30]. Only recently have data emerged on the specific sites of carbonylation in proteins subjected to oxidative stress [31-33]. The best data come from recent work by Mirzaei and Regnier [31, 32], who have identified carbonylation sites in proteins isolated from yeast and rats subjected to in vivo oxidative stress and in model protein oxidation systems. The sites of protein carbonylation represents an important issue

Published online June 5, 2006

Address reprint requests to Dr. S. Gronert, Department of Chemistry and Biochemistry, San Francisco State University, 1600 Holloway Ave., San Francisco, CA 94132, USA. E-mail: sgronert@sfsu.edu because the factors that govern the selective carbonylation of proteins in vivo are likely to be manifested in the carbonylation site selectivity of a given protein. It is our hypothesis that the carbonylation of a protein is site selective and that structural features in the protein will determine the preferred sites of carbonylation.

Although headway has been made in identifying the sites of other oxidative modifications in proteins such as histidine oxidation [34-39] and tyrosine nitration [40, $41]$, the development of techniques for identifying carbonylation sites in proteins has lagged behind. The high reactivity of aldehydes, particularly in the presence of the nucleophilic groups typically found in peptides, complicates their identification and therefore a tagging procedure is needed to protect the functional group for subsequent analysis.

In the present contribution, we describe a mass spectrometric analysis of human serum albumin (HSA) subjected to in vitro oxidative stress. Our methodology is based on that developed by Regnier and coworkers $[26,31]$ recently. We have chosen HSA because serum albumin is a known target of in vivo protein carbonylation [42]. Oxidative stress was simulated by subjecting the protein to metal-catalyzed oxidation (MCO) conditions as well as direct treatment with hypochlorous acid $(\mathrm{HOCl})$. After oxidation, biotin hydrazide followed by $\mathrm{NaBH}_{3} \mathrm{CN}$ was used to label and protect the protein carbonyls in the samples as hydrazines (Scheme 2). In this study, the labeling was simply used to stabilize the oxidative modifications. The biotin label was chosen 


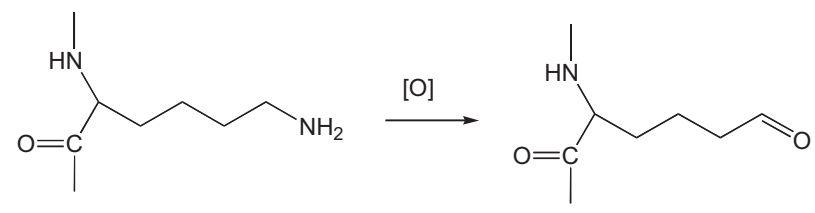

Scheme 1. Oxidation of lysine residue to 2-aminoadipic semialdehyde.

because it could allow for affinity chromatography as a means of concentrating the oxidized protein. Mass spectrometric analysis of peptides from proteolytic digests of the oxidized/labeled proteins allowed for the identification of the specific sites of modification. In these studies, we have focused on two modifications leading to carbonyls, the oxidation of lysine to 2aminoadipic semi-aldehyde (Scheme 1) and the oxidation of arginine to glutamic semi-aldehyde. The oxidizing conditions employed here are expected to generate other protein modifications such as hydroxylation, chlorination, and oxygen addition (i.e., methionine or histidine oxide formation), but the present study will only focus on carbonylation because site selectivity is our area of greatest interest and it has been studied the least in the past. As a part of the analysis of the data, we have correlated the locations of the carbonylation sites with structural features in the protein.

\section{Materials and Methods}

\section{Materials}

Human serum albumin (HSA), biotin hydrazide, and 2,4-dinitrophenylhydrazine (2,4-DNPH) were purchased from Sigma (St. Louis, MO). Sodium cyanoborohydride (5 $\mathrm{M}$ solution in aqueous $1 \mathrm{M}$ sodium hydroxide) was obtained from Sigma-Aldrich (St. Louis, MO). Sodium hypochlorite $(4-6 \% \mathrm{NaOCl})$ was purchased from Fisher Scientific (Fair Lawn, NJ). Sequencing grade, modified trypsin used for the enzymatic digestion was obtained from Promega (Madison, WI). Chymotrypsin and endoproteinase Glu-C were obtained from Roche (Indianapolis, IN). All other chemicals and solvents were obtained from commercial sources and were of the highest purity available.

\section{Oxidation of HSA}

Metal-catalyzed oxidation. HSA (100 mg) was dissolved at a concentration of $10 \mathrm{mg} / \mathrm{mL}$ in oxidation buffer (50 mM HEPES, N-2-hydroxyethylpiperazine$\mathrm{N}^{\prime}$-2- ethanesulfonic acid buffer, $\mathrm{pH}$ 7.4, containing $100 \mathrm{mM} \mathrm{KCl}$ and $10 \mathrm{mM} \mathrm{MgCl}_{2}$ ). The oxidation mixture was prepared by adding neutral ascorbic acid and $\mathrm{FeCl}_{3}$ to a final concentration of $25 \mathrm{mM}$ and $100 \mu \mathrm{M}$, respectively. The mixture was incubated for $72 \mathrm{~h}$ at $37^{\circ} \mathrm{C}$ in a water bath, after which oxidation was terminated by addition of EDTA (ethylenediaminetetraacetic acid) to $1 \mathrm{mM}[26,43]$.
$\mathrm{HOCl}$ oxidation. HSA (20 mg) was dissolved at a concentration of $2 \mathrm{mg} / 1 \mathrm{~mL}$ in HPLC-grade water. Oxidation was performed by adding $\mathrm{NaOCl}$ to a final concentration of $5 \mathrm{mM}$. The mixture was incubated for $15 \mathrm{~min}$ at $37^{\circ} \mathrm{C}$ in a water bath [30]. Following the oxidation, $\mathrm{HOCl}$ was removed by diluting the sample with PBS (phosphate-buffered saline) buffer ( $\mathrm{pH} 7.4$ ) and filtering the solution through a Microcon YM-30 filter device. Filtration was accomplished by centrifugation of the Microcon assembly at $8000 \mathrm{rpm}$ for about 5 to $10 \mathrm{~min}$. The dilution/centrifugation process was repeated four times and subsequently the oxidized HSA sample was dried using a Speed-Vac concentrator.

For both oxidation protocols, controls were prepared by dissolving HSA in HEPES buffer (for MCO oxidation) or in HPLC-grade water (for $\mathrm{HOCl}$ oxidation) and then incubated at $37^{\circ} \mathrm{C}$ in a water bath.

\section{Quantification of Protein Carbonyls in Oxidized $H S A$}

The carbonyl content in oxidized HSA (MCO-HSA and HOCl-HSA) was quantified according to the method developed by Levine et al. [44]. In this method, carbonyl group concentrations were determined by conversion to the corresponding hydrazones by reaction with 10 $\mathrm{mM}$ 2,4-DNPH (protein/2,4-DNPH ratio of 1:5 (vol/ vol) for MCO-HSA and protein/2,4-DNPH ratio of 1:1 (vol/vol) for HOCl-HSA). The reaction mixture was incubated at room temperature for $1 \mathrm{~h}$, with vortexing every $10 \mathrm{~min}$. The protein was then precipitated with trichloroacetic acid (final concentration 10\% vol/vol) and incubated in an ice bath for $30 \mathrm{~min}$. Subsequently, the solution was subjected to centrifugation at $11,000 \times$ $g$ for $3 \mathrm{~min}$, and the supernatant was discarded. The precipitated protein was washed three times with ethanol-ethyl acetate (1:1), and then was dissolved in $1 \mathrm{~mL}$ of $6 \mathrm{M}$ guanidine- $\mathrm{HCl}$ solution ( $\mathrm{pH}$ 2.3). The carbonyl content was calculated from absorbance at $370 \mathrm{~nm}$ using a molar absorption coefficient $(\varepsilon)$ of $22,000 \mathrm{M}^{-1}$ $\mathrm{cm}^{-1}$ [26].

\section{Biotinylation of Protein Carbonyls}

Biotinylation of carbonyl groups in the two types of oxidized HSA (MCO-HSA and HOCl-HSA) was performed by reaction with biotin hydrazide using an approach based on the method of Yoo and Regnier [26]. In summary, the oxidized protein samples were dried using a Speed-Vac Concentrator, then dissolved at a concentration of $2 \mathrm{mg} / \mathrm{mL}$ in PBS buffer ( $\mathrm{pH} 7.4$ ) containing $5 \mathrm{mM}$ biotin hydrazide. The samples were

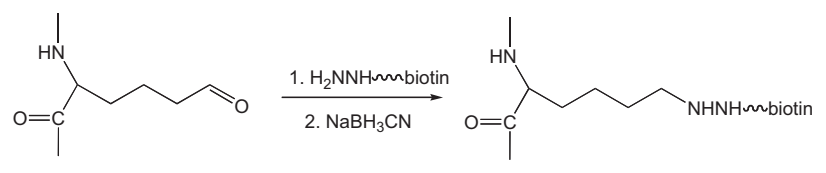

Scheme 2. Labeling of 2-aminoadipic semi-aldehyde. 
incubated at room temperature for $2 \mathrm{~h}$ with shaking and then cooled to $0{ }^{\circ} \mathrm{C}$. An equal volume of $30 \mathrm{mM}$ sodium cyanoborohydride in PBS buffer was subsequently added to stabilize the reaction products [26]. Following the biotin labeling, the HSA samples were precipitated with $20 \%$ trichloroacetic acid in an ice bath for $1 \mathrm{~h}$, and the excess reagents were removed as a part of supernatant. The pellets were washed three times with ethanolethyl acetate (1:1) and then dissolved in ammonium bicarbonate buffer in preparation for enzymatic digestion. In a set of test runs, the biotinylated protein samples were preconcentrated by using a monomeric avidin column (Pierce Biotechnology, Rockford, IL) to separate out the biotinylated proteins. This process did not result in enhanced sensitivity in the LC/MS runs. Because we are working with a single protein with moderately high levels of oxidation, it is not surprising that this preconcentration scheme offered little advantage. The avidin preconcentration was not used in production runs.

\section{Enzymatic Digestion}

The biotinylated HSA samples in $50 \mathrm{mM}$ ammonium bicarbonate buffer at a concentration of $1 \mathrm{mg} / \mathrm{mL}$ were reduced with $30 \mathrm{mM}$ dithiothreitol at $50{ }^{\circ} \mathrm{C}$ for $20 \mathrm{~min}$ and alkylated with $55 \mathrm{mM}$ iodoacetamide at roomtemperature for $30 \mathrm{~min}$ in the dark. The excess of dithiothreitol and iodoacetamide were removed using a Microcon YM-30 filter device at $8000 \times g$ for $15 \mathrm{~min}$. The proteins were redissolved in $50 \mathrm{mM}$ ammonium bicarbonate, and subsequently digested with trypsin (substrate/enzyme ratio of $40 / 1, \mathrm{wt} / \mathrm{wt}$ ) at $37^{\circ} \mathrm{C}$ for $24 \mathrm{~h}$. The digestion was terminated by adding $0.1 \%$ formic acid $(120 \mu \mathrm{L})$, and the solution was stored at $-20^{\circ} \mathrm{C}$. To increase the amino acid sequence coverage, proteins were also digested with chymotrypsin (substrate/enzyme ratio of 50:1, wt/wt) and endoproteinase Glu-C (substrate/enzyme ratio of 50:1, wt/wt). In most work, we have used urea to increase the sequence coverage in digestions. However, we have found that in the specific case of human serum albumin, addition of urea does not have a significant effect on in the sequence coverage in sample digestions (more than $81 \%$ sequence coverage is obtained). Therefore, we did not use urea in our experimental procedures.

\section{Identification of Modified Lys Residues and Tryptic Peptide Sequences by LC/ESI-MS/MS Analysis}

Liquid chromatography/electrospray ionization-tandem mass spectrometry (LC/ESI-MS/MS) analysis of digested HSA samples (50 pmol/injection) was performed using a capillary HPLC system (Micro-Tech Scientific, Vista, CA) connected to an LCQ ion trap mass spectrometer (ThermoFinnigan, San Jose, CA) with a nanospray source [45]. Tryptic peptides were separated by reverse-phase chromatography on a C18 column (75 $\mu \mathrm{m} \times 100 \mathrm{~mm}$; Nucleosil, $5 \mu \mathrm{m}$ particle size) at a flow rate of $0.3 \mu \mathrm{l} / \mathrm{min}$. The digested peptides were eluted from the column using a mobile phase A $(0.1 \%$ formic acid in water) and a mobile phase B $(0.1 \%$ formic acid in acetonitrile) with a three-step linear gradient. The gradient was held for the first $10 \mathrm{~min}$ at $5 \% \mathrm{~B}$, then increased to $35 \% \mathrm{~B}$ in the next $45 \mathrm{~min}$, and finally increased to $50 \% \mathrm{~B}$ in the last $10 \mathrm{~min}$. The eluted peptides (singly, doubly, or triply charged ions) were analyzed using a data-dependent scan procedure with a cyclic series of three different scan modes: a full scan mode (to obtain the most intense peak), followed by a zoom scan mode (to determine the charged state of the precursor ion), and finally an MS/MS scan mode (to determine the structural fragment ions of the precursor ion). To exclude the redundant processing of a few dominant ions in the MS/MS analyses, a dynamic exclusion feature was used that only allows a particular $\mathrm{m} / \mathrm{z}$ value to be processed twice in a $2 \mathrm{~min}$ time window. To ensure that low abundance, oxidized lysine or arginine containing peptides were not left out from our detection scheme, data dependent scan experiments also were completed targeting a list of 50 potential peptide masses that might be expected based on the protein sequence. The acquired MS/MS spectra were then searched against the NCBI nonredundant protein database using the Finnigan Bioworks v.3.2 (Sequest) software. The database searching was set to only consider peptides within the mass range 500-4000 Da. Up to two missed cleavage sites were allowed, and cysteines were defined as modified with carbamidomethylation. To search for oxidized peptides, the differential modifications of methionine, histidine, threonine, serine, proline, lysine, and arginine were set to 16,16 , 240, 258, 241, and $199 \mathrm{Da}$, respectively. The masses of modifications can be found in UNIMOD web site (www.unimod.org).

Experiments (i.e., oxidation. labeling, and analysis) were repeated at least two times (generally three) to ensure reproducibility in the data. In addition, control experiments were completed in the absence of oxidants.

\section{Results}

HSA is a $66 \mathrm{kDa}$ protein with 59 lysine and 24 arginine residues in its secreted form. Its precursor protein contains 609 amino acids (SwissProt P02768), whereas the secreted form is missing the first 24 residues and contains 585 amino acids. Throughout the discussion, residue numbers from the precursor protein will be used and these designators will be 24 units larger than those for the active protein. A sequence map for HSA is given in Figure 1. Crystal structures have been solved for HSA and they will be employed in the discussion of structural motifs [46, 47]. 
Figure 1. Amino acid sequence of human serum albumin precursor protein (SwissProt P02768). Lysines modified by MCO shown in bold and lysines modified by $\mathrm{HOCl}$ shown in bold italics.

\section{Oxidations}

The oxidation of HSA under MCO conditions was efficient and on the basis of 2,4-dinitrophenylhydrazine assays, produced an approximate yield of $45 \mathrm{nmol}$ of bound carbonyls per mg of protein. Because hypochlorous acid is a more active oxidant, shorter reaction times were used and higher yields of bound carbonyls were obtained ( $120 \mathrm{nmol}$ per $\mathrm{mg}$ of protein). These levels are consistent with previous yields from in vitro protein oxidations [26, 30,48].

\section{Analysis of HSA Subjected to MCO Conditions}

The oxidation of a lysine or arginine residue followed by reductive labeling with biotin hydrazide leads to a predictable increase in the mass of the residue. In the case of a lysine residue, it is converted to 2-aminoadipic semi-aldehyde by the oxidation (net mass loss of $1 \mathrm{Da}$ ). The biotin hydrazide label, after reduction of the intermediate hydrazone with $\mathrm{NaBH}_{3} \mathrm{CN}$, adds $242 \mathrm{Da}$ for a net mass shift of $241 \mathrm{Da}$ compared to lysine. In the case of arginine, the oxidation and labeling causes a mass shift of 199 Da compared to the starting residue mass. These altered masses then are incorporated into the BIOWORKS program used to automatically interpret the tandem mass spectra generated for the peptides from the tryptic digests of the oxidized protein. The combined digest data provided greater than $93 \%$ sequence coverage for the samples subjected to MCO. As a result, the great majority of lysine and arginine residues in HSA was characterized in the peptide mixtures from the digests (54/59 lysines and 20/24 arginines were observed).

Using the SEQUEST algorithm in the BIOWORKS software package, we identified two peptides from HSA with mass shifts consistent with lysine modifications. These peptides spanned residues 89-105 and 185-198. The latter peptide gave a weaker relative signal (7-fold less intense), which was difficult to detect and suggests that it is a less common modification in the protein. The peptide containing biotinylated Lys-97 (AA 89-105) was detected at $m / z 1087.1$ for a doublycharged ion (Figure 2), which matches well the calculated mass of $2173.2 \mathrm{Da}$. To confirm the modification sites in these peptides, fragmentation spectra (MS/MS) were used. MS/MS analysis of the precursor ion at $\mathrm{m} / \mathrm{z}$ 1087.1 (Figure 3) leads to a fairly comprehensive set of singly-charged $y$ and $b$ ions $\left(y_{4}-y_{15}\right.$ and $\left.b_{4}-b_{6}, b_{8}-b_{16}\right)$. These fragment ions clearly confirm the sequence of the peptide. The large mass gap (label + Lys, $241+128=$ $369 \mathrm{Da}$ ) between the $\mathrm{y}_{8}$ and the $\mathrm{y}_{9}$ ions (as well as the gap between the $b_{8}$ and $b_{9}$ ions) verifies that Lys-97 was modified and contains the biotin label. The modified lysine in this peptide was skipped in the tryptic digest and formally represents a missed cleavage point. We did locate a nonoxidized peptide spanning residues 89-97 (no missed cleavage points) and it exhibited a higher intensity (20-fold) than the modified peptide spanning residues 89-105; however, the modification can affect ionization efficiency, so an accurate quantitative comparison is not possible. The peptide spanning residues 185-198 was also detected as a doubly protonated ion at $\mathrm{m} / \mathrm{z}$ 952.6. The fragmentation spectrum (Figure 4) shows a less complete set of b and y ions, but the data are sufficient to confirm the sequence of the

H-S-L-H-T-L-F-G-D-K*97-L-C-T-V-A-T-L-R-OH

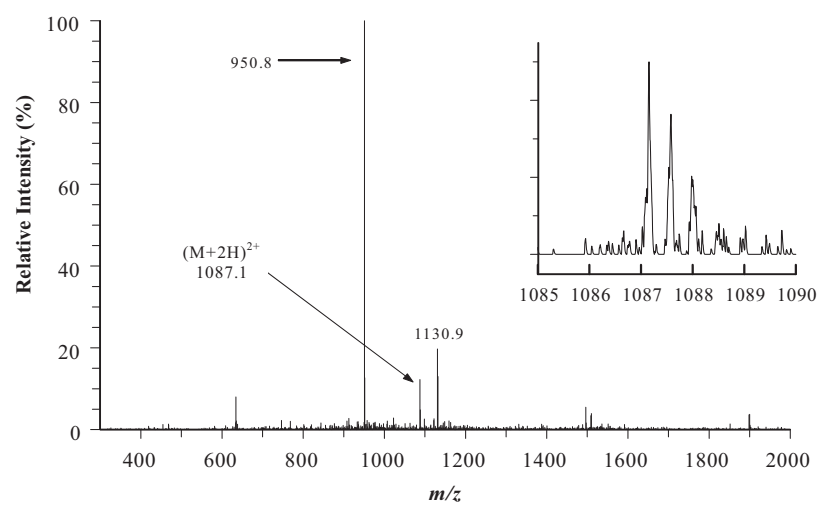

Figure 2. Full scan mass spectrum and the corresponding inset zoom scan of the AA\# 89-105 containing peptide. This figure shows that Lys-97 is labeled with biotin with a doubly charged ion at $m / z$ 1087.1. The asterisk represents the biotin labeled Lys-97. 


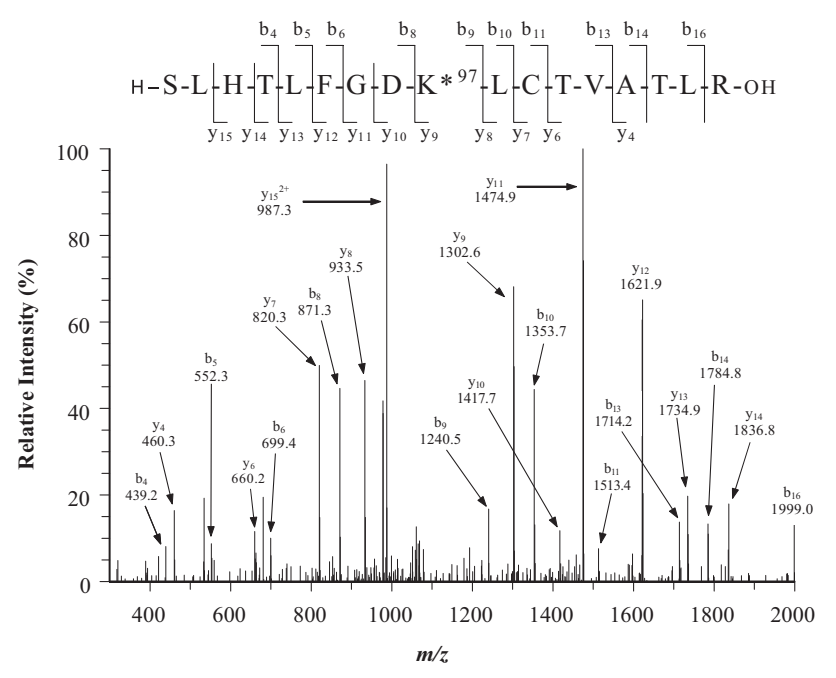

Figure 3. MS/MS spectrum of the AA\# 89-105 containing peptide. The corresponding MS/MS spectrum for $m / z 1087.1$ confirms that the dominant fragments, $y_{n}(n=8-15), b_{8}$, and $b_{10}$, arise from the biotin-labeled Lys-97 containing peptide, with the mass difference between $\mathrm{y}_{9}$ and $\mathrm{y}_{8}$ equals a molecular mass of 128 (Lys) + 241 (biotin) $=369 \mathrm{Da}$.

peptide as well as the modification site. Again the modified lysine represents a missed cleavage point. This lysine is located near the $\mathrm{N}$-terminus of the peptide at Lys residue number 186. Despite the low signals associated with this modified peptide, it was possible to identify it in replicate runs.

In addition to the oxidation of lysine, mass spectrometry also provided evidence of methionine oxidation in the protein. However, we did not identify any examples of arginine oxidation to glutamic semi-aldehyde under these conditions, despite the presence of 24 arginine residues in HSA.

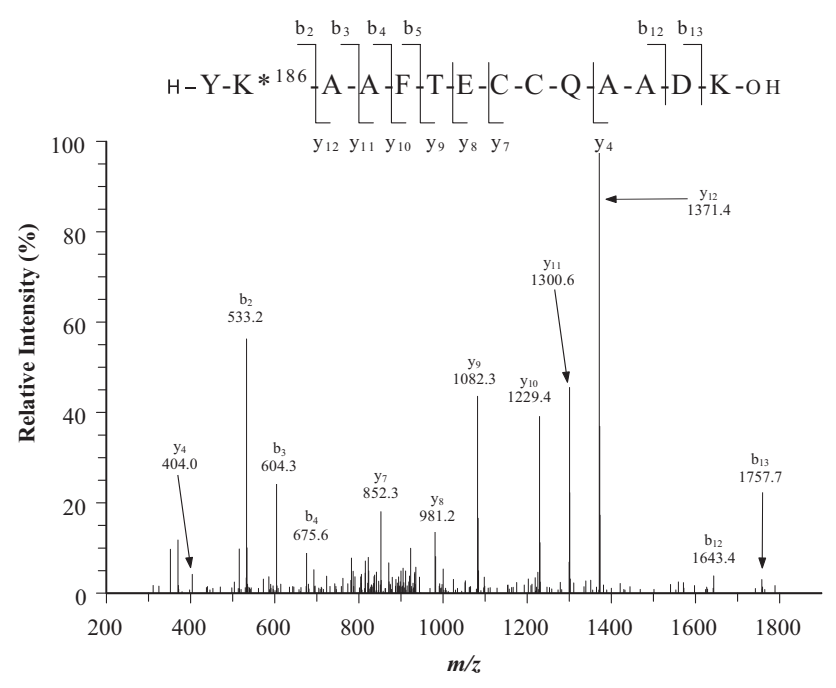

Figure 4. MS/MS spectrum of the AA\# 185-198 containing peptide confirms that Lys-186 is modified with biotin reagent.

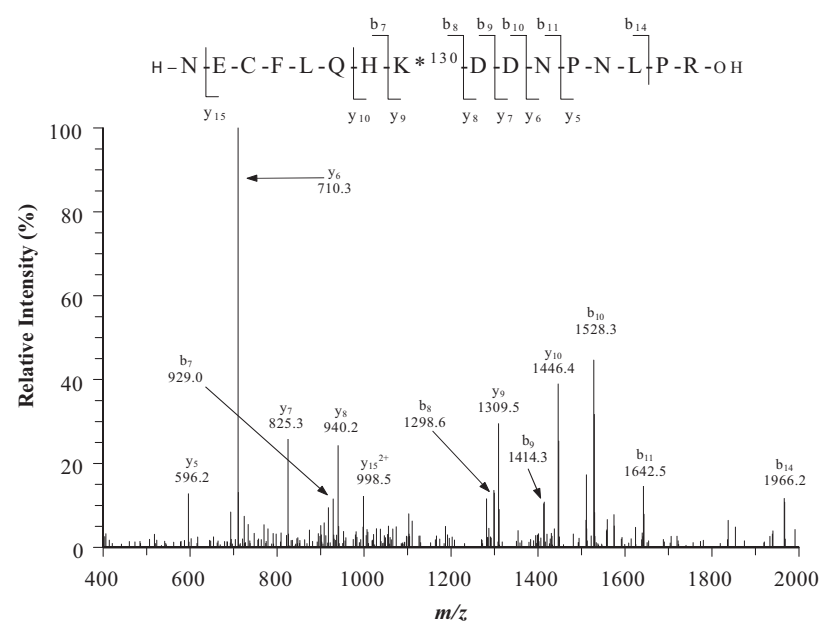

Figure 5. MS/MS spectrum of the AA\# 123-138 containing peptide at $m / z 1119.8$ confirms that Lys-130 is modified with biotin reagent.

\section{Analysis of HSA Subjected to $\mathrm{HOCl}$}

There was good sequence coverage $(86 \%)$ from the combined digest data on the samples from the oxidation of HSA with HOCl. The somewhat lower coverage in the $\mathrm{HOCl}$ samples is probably a result of the stronger oxidant causing a broader range of predictable as well as unpredictable modifications to the protein, which resulted in more complex digest mixtures. Nonetheless, the great majority of lysines and arginines was observed (49/59 lysines and 17/24 arginines were observed). In the analysis of $\mathrm{HOCl}$-oxidized protein with the LCQ, a greater number of modified peptides was identified. Five peptides, spanning residues 123-138, 250-264, 438-452, 497-508, and 598-609, had masses consistent with a labeled lysine. In this case, all the peptides had fairly similar intensities, which were less intense than related nonoxidized peptides. Fragmentation spectra for these peptides are shown in Figure 5, Figure 6, Figure 7, Figure 8, and Figure 9. The MS/MS spectrum of $\mathrm{m} / \mathrm{z} 1119.8$ generated from the doublyprotonated peptide spanning residues 123-138 (Figure 5) shows a large gap ( $369 \mathrm{Da}$ ) between its $\mathrm{y}_{7}$ and $\mathrm{y}_{8}$ ions, and between its $b_{7}$ and $b_{8}$ ions that demonstrates that Lys130 is modified with biotin. In the peptide spanning residues 250-264 (Figure 6), the doubly-protonated peptide $(m / z$ 946.6) gives a large gap (369 Da) between its $y_{7}$ and $y_{8}$ ions that indicates that Lys-257 is modified and is a missed cleavage point. The doubly-protonated peptide $(\mathrm{m} / \mathrm{z}$ 941.1) spanning residues $438-452$ gives a less informative fragmentation spectrum (Figure 7), but it is adequate to verify the sequence as well as the site of modification, Lys-438 at the N-terminus of this peptide. The fragmentation spectrum from the doubly-protonated peptide $(\mathrm{m} / \mathrm{z}$ 854.5) spanning residues $497-508$ (Figure 8) gives a diagnostic mass difference of $369 \mathrm{Da}$ between the doubly-charged $\mathrm{y}_{10}$ ion and the singlycharged $\mathrm{y}_{9}$ ion that definitively identifies the site of modification as Lys-499, another missed cleavage point. 


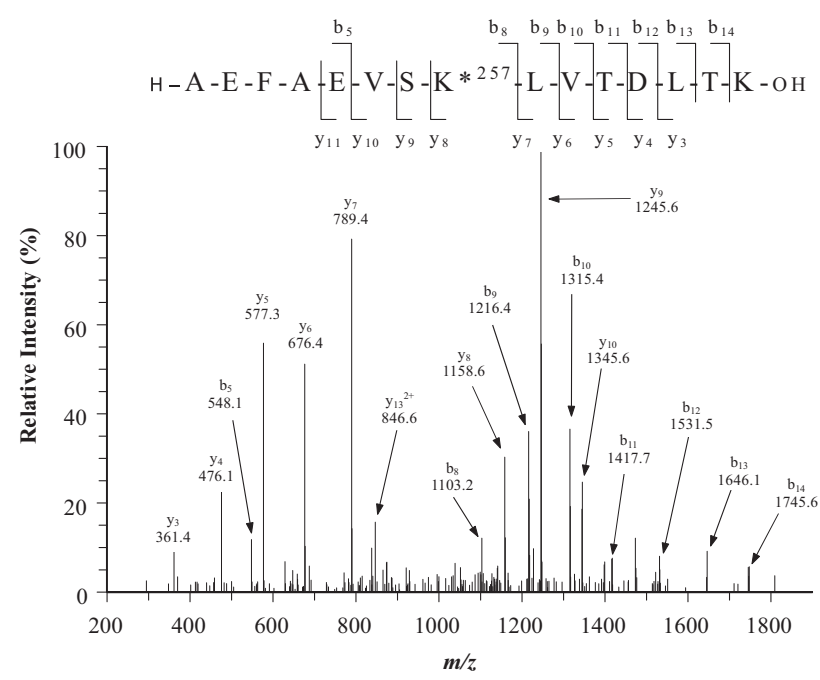

Figure 6. MS/MS spectrum for $m / z 946.6$ shows that the dominant fragments, $\mathrm{y}_{\mathrm{n}}(n=5-11)$, arise from the biotinylated Lys-257 containing peptide (AA\# 250-264).

Finally, fragmentation of the singly-protonated peptide $(\mathrm{m} / \mathrm{z}$ 1382.7) spanning residues 598-609 (Figure 9) gives a useful set of $b$ ions $\left(b_{4}, b_{5}\right.$, and $\left.b_{7-12}\right)$ that confirms the sequence and suggests modification at Lys-598.

A peptide with a mass corresponding to a peptide spanning residues 301-310 with a modified lysine was also identified. However, the fragmentation spectra suggest instead that it is a peptide spanning residues 299-310. By coincidence, the mass shift associated with a biotin-labeled 2-aminoadipic semi-aldehyde residue (lysine oxidation product) is equal to the combined masses of a leucine/isoleucine and a lysine. In HSA, residues 299 and 300 are a leucine and a lysine (residue 298 is another lysine and provides a trypsin cleavage point). Therefore, a peptide spanning residues 301-310 with a modified lysine and one missed cleavage point

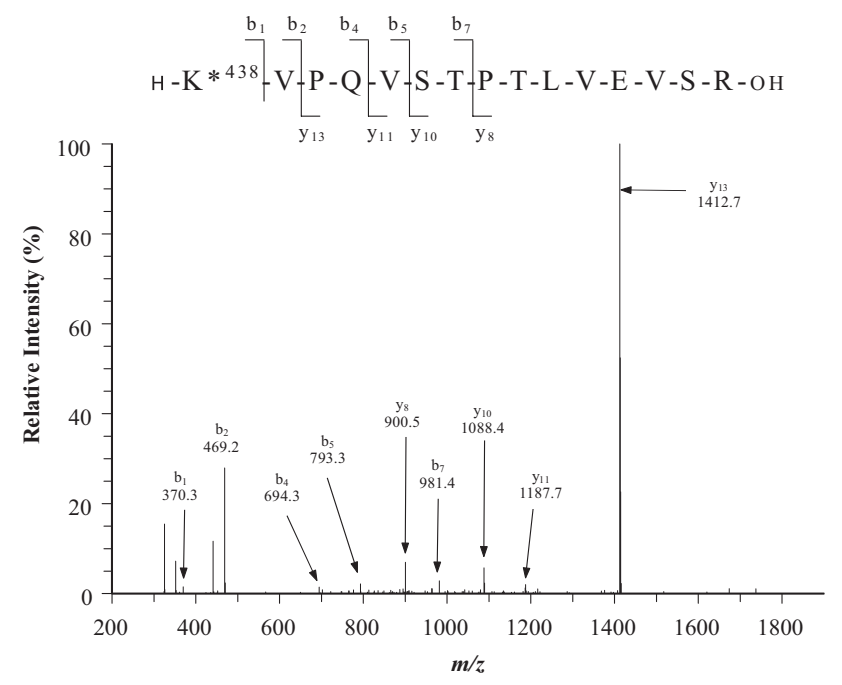

Figure 7. MS/MS spectrum of the AA\# 438-452 containing peptide at $m / z 941.1$ supports that Lys-438 is modified with biotin reagent.

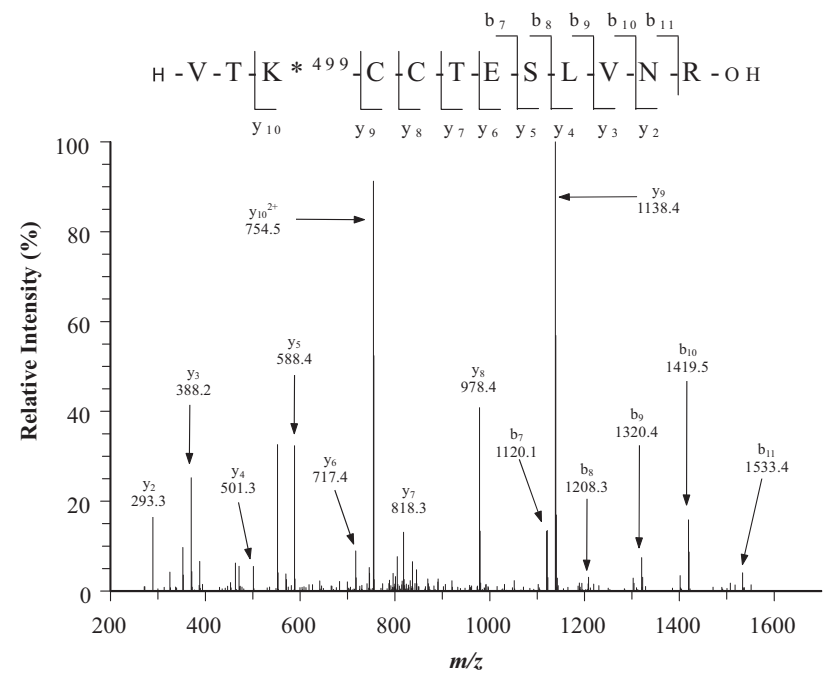

Figure 8. MS/MS spectrum of the AA\# 497-508 containing peptide. The corresponding MS/MS spectrum for $m / z 854.5$ shows that the dominant fragments are $\mathrm{y}_{\mathrm{n}}(n=2-10)$ and $\mathrm{b}_{\mathrm{n}}(n=7-11)$. The mass difference of $369 \mathrm{Da}$ between the singly charged $\mathrm{y}_{9}$ $(1138.4 \mathrm{Da})$ and the doubly charged $\mathrm{y}_{10}(1508 \mathrm{Da})$ at $\mathrm{m} / \mathrm{z} 754.5$ confirms that Lys-499 is modified with biotin reagent.

has the same nominal mass as a peptide spanning residues 299-310 with no modifications and two missed cleavage points. The MS/MS data on this peptide are not conclusive and do not definitively indicate a lysine modification. We found no evidence for the conversion of arginine to glutamic semi-aldehyde under these conditions, but tyrosine chlorination was found at several sites as well as a very weak signal for a proline carbonylation at a single site.

\section{Discussion}

Carbonyl formation in HSA is extremely selective under both sets of oxidation conditions. The protein contains 59 lysine residues, most of which are on the

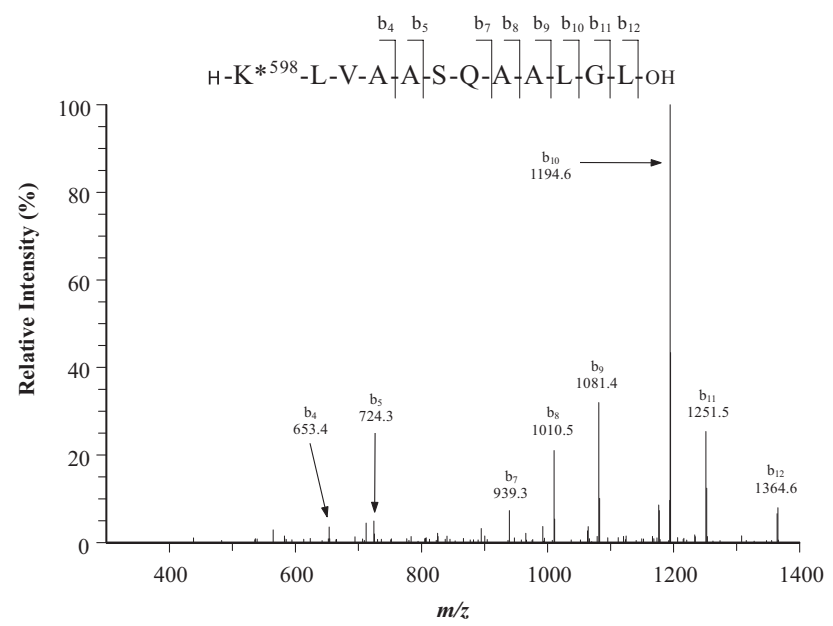

Figure 9. MS/MS spectrum from the C-terminus peptide (AA\# 598-609) supports that Lys-598 is modified with biotin reagent. 
surface, but our mass spectrometric approach only identified two lysines that were modified by MCO. In oxidations using $\mathrm{HOCl}$, only five modified lysine residues were definitively identified, none of which overlapped with the MCO modification sites. Clearly, some structural features in the protein are directing the oxidation and causing the preferential modification of selected lysines. Possibly some level of protein denaturation occurs during the oxidation, disrupting the structure, but this is less likely under the MCO conditions where oxidation levels are low.

In the case of $\mathrm{MCO}$, one might expect that there would be a metal binding site near the location of the lysine modification. HSA is known to bind transition metals and the N-terminus, including His-27, has been identified as a $\mathrm{Cu}^{+2} / \mathrm{Ni}^{+2}$ binding site [49-51]. In addition, there are data that suggest other binding sites in HSA [52-54]. His-91 and His-271 have been suggested as ligands for a $\mathrm{Zn}^{+2}$ binding site [55]. His-129 and His-170 also have been suggested as ligands for transition-metal ions [52]. Crystal structures are available $[46,47]$ and recent work has shown that these structures are consistent with data obtained in solution for the protein [56]. In the crystal structures, Lys-97 is located near the residues of the $\mathrm{N}$-terminus of the secreted protein, but not in the region of the proposed binding site (i.e., near His-27). Although residues 1-28 are not included in the crystal structure, the position of the next residue, Ser-29, suggests that the $\mathrm{N}$-terminal residues of the secreted protein (i.e., His-27) would be far from Lys-97. In fact, Ser-29 is over $10 \AA$ from Lys-97. There are no histidines on the surface of the protein in the vicinity of Lys-97. The most notable structural feature near Lys-97 is a collection of acidic residues and an asparagine, Glu-84, Asn-85, and Asp-96, which could work together to provide a metal binding site. A similar situation is seen with Lys-186. There are no histidines on the surface near this lysine, but a group of acidic residues is located in the vicinity (Glu- 41 , Glu-155, and Glu-156) and could provide a metal binding site for the oxidation reaction. Again, none of the previously proposed binding sites is associated with this residue. However, the lack of lysine oxidation in the vicinity of the proposed metal binding sites (specifically, the $\mathrm{Cu} / \mathrm{Ni}$ site identified by Laussac and Sarkar [50] and the $\mathrm{Zn}$ site identified by Sadler et al. [49] is not surprising because neither of these sites offers a nearby, exposed lysine. The potential metal binding sites that we have identified near the modified lysines are not truly optimal, but the combination of modest metal binding and the close proximity of an exposed lysine could make these sites favorable for oxidation leading to carbonyl formation. One might argue that other functional groups in the protein are competing for the oxidant and therefore the site selectivity is partially driven by the presence or absence of nearby, easily-oxidized groups (i.e., some lysines are protected by having residues such as methionine in close proximity). However, HSA has only six methionines in its expressed form and only eight of the lysines in HSA are within $7 \AA$ of any of these methionines. There is only one free cysteine in HSA and it is not near any lysines $(<7 \AA)$. Consequently, most of the lysines are not protected in this way. In any case, the present results indicate that Lys-97 and Lys-186 are kinetically the most reactive residues for carbonyl formation in HSA treated under MCO conditions. Possibly, modified peptides with relatively weak signals were not detected in our data-dependent scans, but we have manually probed for specific, likely peptides in the LC runs and not found additional modifications (lysine or arginine). Consequently, apparently other carbonyl products occur in considerably lower concentrations than the two that we have directly identified.

In the protein treated with $\mathrm{HOCl}$, the identified sites have some common features. The major one is the presence of at least one, nearby acidic residue (Asp or Glu) that could form a salt bridge to the lysine that is oxidized. For Lys-257, the acid group of Asp-261 is nearby as well as the functional groups of Glu-254 and Tyr-287. In the case of Lys-438, Glu-516 and Tyr-435 are close to the lysine's amino group. For Lys-499, there is a close interaction with the acid group of Glu-503 as well as longer distance one with Asp-495. Lys-598 can interact with Glu-595 or Glu-594. The situation is less clear with Lys-130 because the crystal structure does not indicate any specific interactions for the lysine amino group; however, Glu-124 and Asp-132 are in close proximity and salt bridge interactions could be developed with relatively minor conformation changes. The need for a nearby proton donor/acceptor is consistent with the mechanism of amine oxidation by $\mathrm{HOCl}$ [57]. First, the ammonium ion of the lysine side-chain must be converted to a free amine by deprotonation. This step frees the nitrogen lone pair to interact with the oxygen of $\mathrm{HOCl}$. Second, proton transfers are involved in the oxygen addition process and the formation of the initial hydroxylamine intermediate and its subsequent conversion to an imine. Each of these steps would be aided by the presence of one or more nearby proton acceptor/donors (i.e., acidic residues). However, this type of structural motif is not completely unique to these sites and it is not clear what other factors distinguish them from the other lysines with nearby acidic residues. In general, apparently there is much less selectivity in the $\mathrm{HOCl}$ oxidations and factors such as surface accessibility are playing a role also. Because oxidation levels are relatively high in the $\mathrm{HOCl}$ samples, there is also the possibility that highly modified peptides (i.e., multiple oxidation sites) would not be identified in the data analysis. Moreover, we have some evidence that there are additional lysine modification sites in the $\mathrm{HOCl}$ samples that yield signals too weak to be identified using our present LC/MS equipment and data analysis strategy. 
The absence of arginine oxidation to glutamic semialdehyde suggests that this process is slower than lysine oxidation in HSA when $\mathrm{MCO}$ and $\mathrm{HOCl}$ are the oxidants. Possibly, arginine oxidation is occurring to some extent, but is below our present detectability level. In our mass spectrometry method, low concentration species that coelute with higher concentration species are neglected in the scanning routine and therefore ignored in the analysis. With respect to quantitation, our labeling/mass spectrometric analysis only provides a crude measure of relative oxidation yields based on the intensity of the modified peptide in the spectrum. Although we had relatively high levels of carbonyl formation based on the 2,4-DNPH assays (3-8 carbonyls for every protein molecule), the intensity of the biotin-labeled peptides was relatively weak. This may be the result of poor ionization of these species or a poor conversion of these species to biotinylated, tryptic peptides. Methods that include quantitation and higher sensitivity are under development in the laboratory and will be used to address these questions.

\section{Conclusions}

In this study, the specific sites of carbonyl formation in proteins subjected to oxidative stress have been identified. The generation of protein carbonyls in HSA by metal-catalyzed oxidation (MCO) is highly selective and only two of the 59 lysine residues were identified by our approach as being oxidized to 2-aminoadipic semi-aldehyde. Each of these sites appears to have nearby residues capable of binding a metal ion. With $\mathrm{HOCl}$, five different sites were identified by our methodology. Each of these sites was characterized by a strong interaction with a nearby acidic residue. The fact that only a subset of lysine residues was affected and that the site of attack depends on the nature of the oxidant, points to processes with specific structural requirements. Given that there is strong site selectivity in the oxidation of a given protein, it is not surprising that protein carbonyl formation is only realized in a subset of proteins subjected in vivo to oxidative stress. The present data for HSA are not sufficiently general or representative to define specific structural motifs that are necessary for the preferential carbonylation of proteins under oxidative stress. Studies with other proteins are underway as well as experiments aimed at quantifying oxidation at particular sites in a protein. The results will be reported shortly.

\section{Acknowledgments}

This work was supported in part by funding from a grant (P20 MD000262) from the Research Infrastructure in Minority Institutions Program, National Center on Minority Health and Health Disparities (NCMHD), NIH. The authors also gratefully acknowledge support from the National Institutes of Health (NIH MBRS SCORE 5 SO6 GM52588).

\section{References}

1. Stadtman, E. R. Role of Oxidized Amino Acids in Protein Breakdown and Stability. Methods Enzymol. 1995, 258, 379.

2. Stadtman, E. R.; Levine, R. L. Protein Oxidation. Ann. N.Y. Acad. Sci. 2000, 899, 191.

3. Hawkins, C. L.; Pattison, D. I.; Davies, M. J. Hypochlorite-Induced Oxidation of Amino Acids, Peptides, and Proteins. Amino Acids 2003, 25, 259.

4. Levine, R. L.; Stadtman, E. R. Oxidative Modification of Proteins During Aging. Exp. Gerontol. 2001, 36, 1495.

5. Beal, M. F. Oxidatively Modified Proteins in Aging and Disease. Free Rad. Biol. Med. 2002, 32, 797.

6. Dalle-Donne, I.; Giustarini, D.; Colombo, R.; Rossi, R.; Milzani, A. Protein Carbonylation in Human Diseases. Trends Mol. Med. 2003, 9, 169.

7. Levine, R. L. Carbonyl Modified Proteins in Cellular Regulation, Aging, and Disease. Free Rad. Biol. Med. 2002, 32, 790

8. Sohal, R. S. Oxidative Stress Hypothesis of Aging. Free Rad. Biol. Med. 2002, 33, 573

9. Yan, L. J.; Sohal, R. S. Prevention of Flight Activity Prolongs the Life Span of the Housefly, Musca Domestica, and Attenuates the AgeAssociated Oxidative Damage to Specific Mitochondrial Proteins. Free Rad. Biol. Med. 2000, 29, 1143.

10. Youngman, L. D.; Park, J. Y.; Ames, B. N. Protein Oxidation Associated with Aging is Reduced by Dietary Restriction of Protein or Calories. Proc. Natl. Acad. Sci. U.S.A. 1992, 89, 9112.

11. Sohal, R. S.; Agarwal, S.; Dubey, A.; Orr, W. C. Protein Oxidative Damage is Associated with Life Expectancy of Houseflies. Proc. Natl. Acad. Sci. U.S.A. 1993, 90, 7255.

12. Requena, J. R.; Chao, C. C.; Levine, R. L.; Stadtman, E. R. Glutamic and Aminoadipic Semialdehydes are the Main Carbonyl Products of MetalCatalyzed Oxidation of Proteins. Proc. Natl. Acad. Sci. U.S.A. 2001, 98, 69.

13. Requena, J. R.; Levine, R. L.; Stadtman, E. R. Recent Advances in the Analysis of Oxidized Proteins. Amino Acids 2003, 25, 221.

14. Yan, L. J.; Levine, R. L.; Sohal, R. S. Oxidative Damage During Aging Targets Mitochondrial Aconitase. Proc. Natl. Acad. Sci. U.S.A. 1997, 11, 168.

15. Yan, L. J.; Levine, R. L.; Sohal, R. S. Effects of Aging and Hyperoxia on Oxidative Damage to Cytochrome $c$ in the Housefly, Musca domestica. Free Rad. Biol. Med. 2000, 29, 90.

16. Yan, L. J.; Orr, W. C.; Sohal, R. S. Identification of Oxidized Proteins Based on Sodium Dodecyl Sulfate-Polyacrylamide Gel Electrophoresis, Immunochemical Detection, Isoelectric Focusing, and Microsequencing. Anal. Biochem. 1998, 263, 67.

17. Yan, L. J.; Sohal, R. S. Mitochondrial Adenine Nucleotide Translocase is Modified Oxidatively During Aging. Proc. Natl. Acad. Sci. U.S.A. 1998, 95, 12896.

18. Cabiscol, E.; Piulats, E.; Echave, P.; Herrero, E.; Ros, J. Oxidative Stress Promotes Specific Protein Damage in Saccharomyces cerevisiae. J. Biol. Chem. 2000, 275, 27393.

19. Linton, S.; Davies, M. J.; Dean, R. T. Protein Oxidation and Aging. Exp. Gerontol. 2001, 36, 1503.

20. Mostertz, J.; Hecker, M. Patterns of Protein Carbonylation Following Oxidative Stress in Wild-Type and SigB Bacillus subtilis Cells. Mol. Genet. Genom. 2003, 269, 640 .

21. Soreghan, B. A.; Yang, F.; Thomas, S. N.; Hsu, J.; Yang, A. J. HighThroughput Proteomic-Based Identification of Oxidatively Induced Protein Carbonylation in Mouse Brain. Pharm. Res. 2003, 20, 1713.

22. England, K.; Cotter, T. Identification of Carbonylated Proteins by MALDI-TOF Mass Spectroscopy Reveals Susceptibility of Er. Biochem. Biophys. Res. Commun. 2004, 320, 123.

23. England, K.; O'Driscoll, C.; Cotter, T. G. Carbonylation of Glycolytic Proteins is a Key Response to Drug-Induced Oxidative Stress and Apoptosis. Cell Death Differ. 2004, 11, 252.

24. Johansson, E.; Olsson, O.; Nystrom, T. Progression and Specificity of Protein Oxidation in the Life Cycle of Arabidopsis thaliana. J. Biol. Chem. 2004, 279, 22204.

25. Magi, B.; Ettorre, A.; Liberatori, S. Bini, L. Andreassi, M.; Frosali, S.; Neri, P.; Pallini, V.; Di Stefano, A. Selectivity of Protein Carbonylation in the Apoptotic Response to Oxidative Stress Associated with Photodynamic Therapy: A Cell Biochemical and Proteomic Investigation. Cell Death Differ. 2004, 11, 842.

26. Yoo, Y. S.; Regnier, F. E. Proteomic Analysis of Carbonylated Proteins in Two-Dimensional Gel Electrophoresis Using Avidin-Fluorescein Affinity Staining. Electrophoresis 2004, 25, 1334.

27. Dalle-Donne, I.; Scaloni, A.; Giustarini, D.; Cavarra, E.; Tell, G.; Lungarella, G.; Colombo, R.; Rossi, R.; Milzani, A. Proteins as Biomarkers of Oxidative/Nitrosative Stress in Diseases: The Contribution of Redox Proteomics. Mass Spectrom. Rev. 2005, 24, 55.

28. Ghezzi, P.; Bonetto, V. Redox Proteomics: Identification of Oxidatively Modified Proteins. Proteomics 2003, 3, 1145.

29. Watson, D. G.; Atsriku, C.; Oliveira, E. J. Review Role of Liquid Chromatography-Mass Spectrometry in the Analysis of Oxidation Products and Antioxidants in Biological Systems. Anal. Chim. Acta 2003, 492, 17.

30. Headlam, H. A.; Davies, M. J. Markers of Protein Oxidation: Different Oxidants Give Rise to Variable Yields of Bound and Released Carbonyl Products. Free Rad. Biol. Med. 2004, 36, 1175. 
31. Mirzaei, H.; Regnier, F. E. Affinity Chromatographic Selection of Carbonylated Proteins Followed by Identification of Oxidation Sites Using Tandem Mass Spectrometry. Anal. Chem. 2005, 77, 2386.

32. Mirzaei, H.; Regnier, F. E. Enrichment of Carbonylated Peptides Using Girard P Reagent and Strong Cation Exchange Chromatography. Anal. Chem. 2006, 78, 770

33. Young, N. L.; Lee, S.; Whetstone, P. A.; Butlin, N. G.; Corneillie, T. M.; Cheal, S. M.; Baileyy, C. G.; Zeller, L. C.; Benner, W. H.; Meares, C. F.; Lebrilla, C. B. Proceedings of the 52nd American Society for Mass Spectrometry Conference; Nashville, TN, 2004.

34. Schiewe, A. J.; Margol, L.; Soreghan, B. A.; Thomas, S. N.; Yang, A. J. Rapid Characterization of Amyloid- $\beta$ Side-Chain Oxidation by Tandem Mass Spectrometry and the Scoring Algorithm for Spectral Analysis. Pharm. Res. 2004, 21, 1094.

35. Schoneich, C.; Williams, T. D. Cu(II)-Catalyzed Oxidation of $\beta$-Amyloid Peptide Targets His(13) and His(14) over His(6): Detection of 2-OxoHistidine by HPLC-MS/MS. Chem. Res. Toxicol. 2002, 15, 717.

36. Schoneich, C.; Williams, T. D. Cu(II)-Catalyzed Oxidation of Alzheimer's Disease $\beta$-Amyloid Peptide and Related Sequences: Remarkably Different Selectivities of Neurotoxic $\beta$ Ap1-40 and Nontoxic $\beta$ Ap40-1. Cell. Mol. Biol. 2003, 49, 753 .

37. Kurahashi, T.; Miyazaki, A.; Suwan, S.; Isobe, M. Extensive Investigations on Oxidized Amino Acid Residues in $\mathrm{H}_{2} \mathrm{O}_{2}$-Treated $\mathrm{Cu}$, Zn-Sod Protein with LC-ESI-Q-TOF-MS, MS/MS for the Determination of the Copper-Binding Site. J. Am. Chem. Soc. 2001, 113, 9268

38. Lim, J. Vachet, R. Development of a Methodology Based on MetalCatalyzed Oxidation Reactions and Mass Spectrometry to Determine the Metal Binding Sites in Copper Metalloproteins. Anal. Chem. 2003, 75, 1164.

39. Lim, J.; Vachet, R. Using Mass Spectrometry to Study Copper-Protein Binding under Native and Non-Native Conditions: $\beta$-2-Microglobulin. Anal. Chem. 2004, 76, 3498 .

40. Petersson, A. S.; Steen, H.; Kalume, D. E.; Caidahl, K.; Roepstorff, P. Investigation of Tyrosine Nitration in Proteins by Mass Spectrometry. J. Mass Spectrom. 2001, 36, 616

41. Willard, B. B.; Ruse, C. I.; Keightley, J. A.; Bond, M.; Kinter, M. Site-Specific Quantitation of Protein Nitration Using Liquid Chromatography/Tandem Mass Spectrometry. Anal. Chem. 2003, 75, 2370.

42. Jana, C. K.; Das, N.; Sohal, R. S. Specificity of Age-Related Carbonylation of Plasma Proteins in the Mouse and Rat. Arch. Biochem. Biophys. 2002, 397, 433.

43. Anraku, M.; Yamasaki, K. Effect of Oxidative Stress on the Structure and Function of Human Serum Albumin. Pharm. Res. 2001, 632.

44. Levine, R. L.; Garland, D.; Oliver, C. N.; Amici, A.; Climent, I.; Lenz, A. G.; Ahn, B. W.; Shaltiel, S.; Stadtman, E. R. Determination of
Carbonyl Content in Oxidatively Modified Proteins. Methods Enzymol. 1990, 186, 464.

45. Yen, T. Y.; Yan, H.; Macher, B. A. Characterizing Closely Spaced, Complex Disulfide Bond Patterns in Peptides and Proteins by Liquid Chromatography/Electrospray Ionization Tandem Mass Spectrometry. J. Mass Spectrom. 2002, 37, 15.

46. Bhattacharya, A. A.; Curry, S.; Franks, N. P. Binding of the General Anesthetics Propofol and Halothane to Human Serum Albumin-High Resolution Crystal Structures. J. Biol. Chem. 2000, 275, 38731.

47. Sugio, S.; Kashima, A.; Mochizuki, S.; Noda, M.; Kobayashi, K. Crystal Structure of Human Serum Albumin at 2.5 Angstrom Resolution. Protein Eng. 1999, 12, 439.

48. Adams, S.; Green, P.; Claxton, R.; Simcox, S.; Williams, M. V.; Walsh, K. Leeuwenburgh, C. Reactive Carbonyl Formation by Oxidative and Non-Oxidative Pathways. Front Biosci. 2001, 6, A17.

49. Sadler, P. J.; Tucker, A.; Viles, J. H. Involvement of a Lysine Residue in the N-Terminal $\mathrm{Ni}^{2+}$ and $\mathrm{Cu}^{2+}$ Binding-Site of Serum Albumins Comparison with $\mathrm{Co}^{2+}, \mathrm{Cd}^{2+}$, and $\mathrm{Al}^{3+}$. Eur. J. Biochem. 1994, 220, 193.

50. Laussac, J. P.; Sarkar, B. Characterization of the Copper(II)-Transport and Nickel(II)-Transport Site of Human-Serum Albumin-Studies of Copper(II) and Nickel(II) Binding to Peptide 1-24 of Human-Serum Albumin by C-13 and H-1-NMR Spectroscopy. Biochemistry 1984, 23, 2832.

51. Glennon, J. D.; Sarkar, B. Nickel(II) Transport in Human-Blood SerumStudies of Nickel(II) Binding to Human-Albumin and to NativeSequence Peptide, and Ternary-Complex Formation with L-Histidine. Biochem. J. 1982, 203, 15.

52. Bal, W.; Christodoulou, J.; Sadler, P. J.; Tucker, A. Multi-Metal Binding Site of Serum Albumin. J. Inorg. Biochem. 1998, 70, 33.

53. Goumakos, W.; Laussac, J. P.; Sarkar, B. Binding of Cadmium(II) and Zinc(II) to Human and Dog Serum Albumins-an Equilibrium Dialysis and Cd-113-Nmr Study. Biochem. Cell Biol. 1991, 69, 809.

54. Martins, E. O.; Drakenberg, T. Cadmium(II), Zinc(II), and Copper(II) Ions Binding to Bovine Serum-Albumin-a Cd-113 NMR-Study. Inorg. Chim. Acta 1982, 67, 71 .

55. Stewart, A. J.; Blindauer, C. A.; Berezenko, S.; Sleep, D.; Sadler, P. J. Interdomain Zinc Site on Human Albumin. Proc. Natl. Acad. Sci. U.S.A. 2003, 100, 3701

56. Ferrer, M. L.; Duchowicz, R.; Carrasco, B.; de la Torre, J. G.; Acuna, A. U. The Conformation of Serum Albumin in Solution: A Combined Phosphorescence Depolarization-Hydrodynamic Modeling Study. Biophys. J. 2001, 80, 2422.

57. Matte, D.; Solastiouk, B.; Merlin, A.; Deglise, X. Kinetic-Study of N-Chlorination of Dimethylamine and Diethylamine in an Aqueous Medium. Can. J. Chem. 1989, 67, 786 . 